\title{
La Novela Colombiana en las Dos Ultimas Décadas
}

\author{
Carmiña Navia Velasco \\ Universidad del Cauca. Popayán. Colombia
}

\section{Proceso General}

García Márquez con la publicación de sus primeras obras (La Hojarasca, La Mala Hora, El Coronel no tiene quien le Escriba, Cien Años de Soledad) pone, en Colombia, las condiciones inmediatas para la aparición de la novela moderna. A partir de 1970 (fecha promedio y aproximativa) se generan en el país procesos inmensamente ricos y variados de escritura.

No es posible, ni creo muy útil, realizar una aproximación exhaustiva a las novelas publicadas en Colombia en las dos últimas décadas. (Pineda, 1990) Planteo en este artículo una visión semántica que pretende dar cuenta de los ejes fundamentales de la novelística Colombiana desde 1970. Como punto de partida podemos situar en la globalidad del proceso tres obras que atraviesan el panorama nacional y que significan una escritura enriquecedora y revolucionaria que alimentan e irradian en todo el país.

Son obras que por su formación y aliento universal sintetizan búsquedas, experimentaciones y logros. Estoy hablando de:

El Otoño del Patriarca, Gabriel García Márquez, 1975.

La Tejedora de Coronas, Germán Espinosa, 1982.

Celia se Pudre, Héctor Rojas Erazo, 1986.

Señalemos algunos aspectos comunes, que - más allá de sus diferencias y especificidades - marcan muy profundamente estas tres obras y se proyectan en el panorama nacional:

1. Transformación de la relación, narrador / lector. Nos encontramos frente a tres novelas que rompen definitivamente el esquema de una lectura fácil y complaciente.

El cuadro general de las obras se va armando poco a poco y el lector es obligado a participar en esa armazón. El Otoño, exige un lector que penetre en la selva desmesurada y avance hacia la identificación de actores e historia. La Tejedora, mueve a su lector por una superabundancia de erudición 
e información que le motiva o plantea otras lecturas y búsquedas. Celia, en cambio exige un lector paciente y minucioso capaz de detener y devolver su ritmo de lectura.

Esta escritura entonces nos sitúa frente a un acto de lectura activo cuyo ejercicio de aproximación a los textos está planteado en términos de procesos de producción más complejos que reconstruir el transcurrir de una o varias historias.

2. Estas tres obras se convierten también en paradigmas de una serie de rupturas y explosiones, de los elementos narrativos, que marcan las novelas de estas décadas.

El tiempo se percibe no en su cotidianeidad o transitoriedad lineal y acumulativa, sino que se convierte en un tiempo modificable según la experiencia o la materia de los acontecimientos en juego: cíclico y premonitorio en, El Otoño; denso, condensador, inmensamente rico en, La Tejedora e interior e infinito en, Celia.

Igual cosa ocurre con los espacios. La "parcela" del dictador se convierte en nuestro país y nuestra historia. La Europa de Genoveva Alcocer es la patria universal de todo itinerante del saber. El patio de la casa de Celia se convierte en el alma de todo aquél al que aprisionan sus recuerdos y pasados.

Los personajes explosionan y se hacen símbolos. No podemos asumir como caracteres novelescos, en el sentido de héroes tradicionales, al dictadorpatriarca y su andar inconsciente por el mundo, a la desmesura de edad y experiencias que es Genoveva, al susurrante pasar de los recuerdos que es Celia.

3. Finalmente se trata de novelas que, inscritas en el neobarroco latinoamericano, nos presentan un lenguaje distinto, nuevo, potencial izado hasta el máximo. La lectura de estas obras nos enfrenta a un lenguaje que:

... no es sólo medio de expresión, no sólo principio y fin de lo conformable artísticamente, sino, a la vez, fuente de la inspiración, no sólo forma, sino materia y vivencia. La literatura del manierismo y del barroco no es sólo, como toda obra, un arte vinculado a la palabra y cuyas raices se hallan en el lenguaje, sino, además, un arte que surge del espiritu del lenguaje; un arte que no tanto aporta un contenido al lenguaje, cuanto lo extrae de él. (Hausser, 1974).

De alguna manera podemos decir que estas tres novelas, en sus distintos momentos, funda y fundamentan una nueva lengua literaria nacional.

Me voy a detener ahora en algunos aspectos significativos, algunos ejes que atraviesan este proceso global. 


\section{Desintegración Social y Quiebre del Sujeto}

Una tendencia muy marcada en estos años, especialmente en la década del 70, es la experimentación, la búsqueda de caminos nuevos e inéditos para la narrativa. Experimentación que bajo la influencia de la llamada "nueva novela" se traducirá, como ya señalamos, en el debilitamiento de categorías novelísticas tradicionales tales como personajes o acción, y en la transformación de otras como tiempo o espacio.

La novela deshumanizada es una tendencia dondepor el condiciona miento de una ideología predominante, ya sea la propia del autor o la que reside en la moda literaria, se evita escrupulosamente un contenido que capte al hombre en su problemática vital, alejándose de toda referencia al mundo cotidiano o a los destinos colectivos. En la deshumanización, la problemática se particulariza mediante lo individual. En vez de lo exterior se prefiere lo interior, de modo que el mundo del entorno tal y como es, se reemplaza por una versión subjetiva de los hechos narrados que no va más allá de lo egocéntrico. Además se rechaza el valor del asunto, considerando como caduca la experiencia humana del acontecer; en su lugar se impone el gusto por la novedad... En conjunto lo caracteristico de la deshumanización es la prioridad de la forma sobre el fondo. (Gil, 1990)

Hay dos obras, especialmente logradas, que podemos considerar representativas de esta tendencia en Colombia:

El Álbum Secreto del Sagrado Corazón, de Rodrigo Parra Sandoval y Hojas en el Patio de Darío Ruiz Gómez. Ambas publicadas en 1978.

Se trata de dos novelas diferentes que se inscriben en una misma línea de búsqueda. Escritas en la década del 70 participan de un trasfondo contextual de caídas y pérdidas. El mundo antiguo: semifeudal, católico, conservador, se ha ido desintegrando sin que nuevas formas de convivencia y nuevas referencias axiológicas hayan tomado aliento. En ambas novelas se asiste al resquebrajamiento de los discursos dominantes en el país hasta 1960; el Valle y la Antioquia "señoriales" y su correspondiente bendición católica toca a su fin.

En "El Álbum Secreto del Sagrado Corazón” el discurso rector es el católico en el sentido más puro y tradicional del término: el espacio convocador e irradiador de sentido es un seminario. En las conciencias de los seminaristas (Teófilo? Arnovio?) juegan su juego todos los discursos que constituyen razón de ser y cultura: el religioso, el político, el social, las canciones populares, las historietas, las revistas, las revistas y periódicos, la tradición machista... y en ese diálogo de unos discursos con otros, a lo largo de la conformación del álbum, éstos van mostrando su vaciedad, en ausencia de real significación y de eficacia.

El espacio de sentido queda entonces vacío y en esa vaciedad las referencias axiológicas se hacen trizas. La novela da cuenta de un mundo regido por 
algunas constantes desde el siglo XII (Santa Zita), constantes que se quedan vacías, inoperantes, mundo que se queda sin norte. En esta carencia de sentido los sujetos prácticamente se deshacen, se vuelven voces, sombras, balbuceos. Se confunden en la medida en que sus referencias entran en un proceso de deshilvanación. A un mundo de parámetros claros, corresponde un sujeto coherente; a un mundo de deterioro corresponde, en la propuesta de esta novela, un sujeto en retirada y en quiebre.

Nos encontramos con un proceso similar de desintegración social en la novela de Ruiz Gómez, Hojas en el Patio.

Todo el tiempo y espacio exteriores: retazos de historia, fundaciones, sagas familiares... se viven, miran y evalúan desde el interior. No nos encontramos tanto con conciencias como con sombras o "nombres" que deambulan y se asoman a un mundo que al mismo tiempo se hace y se deshace.

Como las hojas en el patio los discursos se entrecruzan y dialogan los unos con los otros: "Lo contrario de la mentira que íbamos a descubrir después; detrás de esas fachadas, en el interior de esos palacetes, esa hipocresía que oíamos en lágrimas y alaridos en las altas horas de la noche y que nos sigue doliendo porque la patria nuestra, esa infancia ya no existe, no tuvo lugar jamás" (Ruiz, 1978). En ese diálogo de discursos los vemos deshacerse - como las hojas que se arrebata el viento -, desintegrando en ese proceso a los sujetos individuales que primero habían constituido. El discurso que domina la novela es de tipo político: una ética de la convivencia y del poder que se demuestra falsa y que pone de manifiesto su doble juego; con este discurso se conjugan la palabra católica, siempre presente y ese "ser" antioqueño mítico y ocultador de realidades poco luminosas. En esta novela es muy clara la intención de denunciar como falsos los "pilares de nuestra nacionalidad.

\section{El Ciclo Urbano}

En Colombia se escriben novelas de asentamiento y referencialidad urbana desde [males del siglo XIX. El germen de nuestras primeras urbes (Bogotá), con la aparición de cosmovisiones y conflictividades distintas, suscitó en el país algunas obras narrativas que no se pueden desconocer en el momento de evaluar la moderna narrativa urbana.

Diana Cazadora, de Soto Borda, más allá de las aventuras de un héroe engañado y una prostituta semielegante, convierte a la ciudad: sus relaciones, sus calles y lugares, sus faroles de luz, sus angustias e hipocresías... en verdadera protagonista. Algo parecido ocurre con Frutos de mi Tierra, en la que Carrasquilla descubre las ruindades futuras del Medellín de hoy. 
Ya avanzado este siglo, Osorio Lizarazo, se embarca en la aventura de descubrir y explicitar los hilos más ocultos que organizan la vida de Bogotá, en el momento en que la capital está por despegar hacia la modernidad y empieza a ser un polo de atracción para campesinos y jóvenes de sus inmediaciones. La llegada a la ciudad, búsquedas de trabajo, desempleos, los conflictos que empiezan a acumularse... son algunos ejes de sentido que este autor va a trabajar.

En las últimas décadas, quizás desde la publicación de "La Infancia legendaria de Ramiro Cruz" (M. Arrubla) en 1967, las novelas que quieren dar cuenta del lento construir, crecer y decrecer de nuestras ciudades, se multiplican. Pero está claro que Bogotá, Medellín, Cali, y otras urbes menos pobladas, se van constituyendo en entes literarios, cuya textualidad y simbología crece, muchas veces independientemente de sus caminos materiales.

\section{Bogotá}

Algunos narradores y narradoras se ocupan a lo largo de estos años de descubrir y "poner orden" en los acuerdos tácitos que orientan y regulan la convivencia en Bogotá.

La figura de Gaitán y su asesinato el 19 de Abril de 1948, reaparece una y otra vez, constituyéndose en referencia obligada de aconteceres futuros. De las novelas que reconstruyen este origen, me parece muy significativa: "Una y Muchas Guerras" de Alonso Aristizabal, publicada en 1985 por Planeta.

Desde la visión de un narrador niño/joven, va apareciendo esa ciudad que rechaza a los migrantes, en un proceso que estudia muy bien José Luis Romero en su libro "Latinoamérica: Las Ciudades y las Ideas". (Romero, 1984) El destino, el largo camino de Rubelio y Sola, es el destino de una generación para la cual la migración fue en un primer momento el sueño, la expectativa, la posibilidad de vida frente a la violencia... y en un segundo momento la frustración, el puesto que no llega, la promesa que no se cumple, las calles largas y vacías, la casa del silencio...

Bogotá se convierte en esta novela en un polo cuya fuerza de atracción llega a distintos rincones del país y en un polo que expulsa a la juventud hacia la guerra, a los mayores de regreso a su tierra derrotados, a las mujeres a sus propios espacios de marginalidad.

Esa ciudad que se construye sobre el juego de: desde/rechazo (violencia), es luego trabajada en su vida cotidiana por varios novelistas. Me voy a detener en Luis Fayad que a lo largo de quince años rastrea diferentes resquicios y momentos de ese espacio vital. 
En una primera novela: "Los Parientes de Ester" (1978), Fayad penetra en una ciudad gris que sume en el anonimato y aislamiento, a una clase media sin más horizonte que sus pequeñas intrigas y rencillas. (Arévalo, 1994)

En "Compañeros de Viaje" (Tercer Mundo 1991), el espacio bogotano se despliega más ampliamente: la clase media que va del comercio a la profesionalización, la Universidad que reorganiza relaciones e historia, Chapinero y los barrios residenciales de los años 60. El espacio de la Universidad y las relaciones que genera, se convierte en el núcleo que irradia los sueños y las frustraciones de una nueva generación.

Generación que nace en la ciudad, que la considera absolutamente suya, pero cuya voluntad va más allá de terminar o perfeccionar lo que iniciaron los mayores. Generación que en esa voluntad de cambio se pone en el camino de constantes y renovadas conflictividades.

"Compañeros de Viaje" da cuenta de todo ello de una manera directa. Sus protagonistas más fuertes (dos o tres), son enfocados en unos años decisivos de sus historias personales: los años en que se definen y orientan sus vidas. Y la importancia personal de esos años se hace importancia de la Universidad y de la ciudad; las definiciones son para el conjunto social, no sólo para los jóvenes. Al escoger este eje de sentido Fayad penetra en una ciudad nueva que nace y muere dentro de la gran ciudad.

\section{Medellin}

Con la novelística que recrea y genera el espacio: Medellón, entramos en una realidad muy diferente de la anterior. Iniciando la década del 70 (1973), Manuel Mejía Vallejo publica su novela: "Aire de Tango". En muchos aspectos se trata de una novela pionera, muy marcada por el énfasis que la literatura antioqueña pone en la cultura popular.

En las conversaciones, de una o muchas noches de bares, se va reconstruyendo la vida en una Guayaquil que se convierte a su vez en centro de la ciudad de Medellín y en centro de la cultura paisa. Los hechos, personajes, aventuras, recuerdos, nos llegan a través de retazos de conversación, a través de un lenguaje capaz de convocar la vida.

Guayaquil (como parte de la vida urbana), se convierte en el centro al que llegan y del que salen: tangos, canciones, partidos de football, peleas, cuchillos, violaciones, fiestas, mujeres irrespetadas y machos que matan. Los bares en primer lugar y en conjunto del bario además, se constituyen en un microcosmos en el que la violencia no es ya la de las balas y el fuego cruzado de "tierra arrasada", sino que se ha introyectado y subjetivizado de tal manera que 
es el nicho natural de las relaciones interpersonales: relaciones entre amigos y compañeros de trago, relaciones entre hombres y mujeres muy especialmente, relaciones entre los de dentro y fuera del ambiente. Esa violencia atraviesa el lenguaje, las miradas, las evaluaciones sociales, los cuchillos o el revólver. Esa violencia teje las vidas de "Aire de Tango".

Otros aspectos bien interesantes de la vida de nuestras ciudades, son los trabajados por esa novela - corazón de la vida urbana - "Tuyo es mi corazón" de Juan José Hoyos (Planeta 1984). En éste se nos presenta la vida de una generación más o menos contemporánea dela protagonista de «Compañeros de Viaje». Pero se trata de una vida atravesada por parámetros muy distintos. Una vida barrial de costumbres y cultura popular. Un espacio urbano que aparentemente puede ser el revés del barrio Guayaquil: El combo de adolescentes que toman cerveza y miran muchachas, mientras se cuentan sus angustias y sus vidas, el baile de los sábados, el cine, el primer amor. El barbero y el dueño del granero que se convierten en referencia y en «maestros».

Se trata de un conjunto juvenil que no se plantea grandes problemas o profundidades, una vida que transcurre en medio de la sencillez y una cierta ingenuidad. Sin embargo a lo largo de la obra, la violencia va tocando poco a poco la vida de los protagonistas: La violencia familiar de una cultura ancestralmente machista y autoritaria, la violencia del sin sentido y la desorientación juvenil y finalmente la violencia de las bombas y los atentados que terminan por desplazar esa vida sencilla que hemos visto.

\section{Cali}

En la narrativa caleña también podemos visualizar dos momentos de la ciudad. Sus orígenes, el despegue hacia los caminos de la gran urbe. Orígenes profundamente ligados a la violencia y a la migración. "Noche de Pájaros", novela de Arturo Alape, Planeta (1984), recorre y recoge estos inicios.

En esta narración que nos llega principalmente a través de unos ojos aterrorizados y escondidos, asistimos al crecimiento de una ciudad que poco a poco pierde la alegría y la luminosidad de las mañanas de carrileras y de las tardes de baño en Pance, desplazadas por el miedo y la oscuridad como único medio de escondite y de sobrevivencia. Los carros negros de los pájaros se adueñan de las calles y aterrorizan la vida en la ciudad.

Esta novela que aparece a la mitad de la década de los ochenta y que no ha sido muy recogida en Cali, aporta una visión global e interesante sobre la ciudad como espacio vital: No es el Cali salsero y pachanguero de siempre, sino por el contrario una ciudad que esconde amenazas, temor y violencia. 
Una ciudad que guarda en sus entrañas la matanza de un sábado en la noche y que con ese secreto domina la vida de sus habitantes.

La Cali de los años 60 y 70, es trabajada en dos novelas desde ángulos distintos: "Qué viva la Música” de Andrés Caicedo y "El Titiritero" de Gustavo Álvarez Gardeazabal, ambas publicadas en 1977.

Qué viva la Música, se mete a fondo con el lado oscuro de una juventud desorientada, carente de valores, a la que la droga y la música le ganan la batalla y la convierten únicamente en un cuerpo deseante de ritmo y de placer.

La relación con la música es muy original: De un lado el lenguaje que se funde con el ritmo y la letra de las canciones, recogiendo muy bien la vitalidad y renovación lingüística de esa juventud. De otro, la relación música/ ciudad.

La novela se convierte en un itinerario espacial: norte- sur- centro, que es a su vez un itinerario musical: rock salsa, y al mismo tiempo un camino hacia el deterioro.

La novela de Álvarez Gardeazabal por el contrario se mete con otra cara de la misma juventud y de la misma ciudad: La generación que desde la Universidad y desde sus sueños un mundo diferente busca una salida política y no encuentra más que la locura, la violencia y la muerte.

Desde una mirada sociocrítica ambas novelas resultan reveladoras, porque muy tempranamente: 1977, descubren en los hilos ocultos del entramado social, 10 que una década después va a salir a la luz pública: la caída estrepitosa de los valores tradicionales y la guerra cruel, sin tregua y sin sentido que nos azota.

En la narrativa de estas décadas entonces, Bogotá, Medellín y Cali se convierten en espacios vitales específicos: lugares de referencia e identidad, núcleos de relaciones y de convivencias, receptáculos de sueños y esperanzas, realidades de frustraciones y amarguras. Son espacios literarios que cobran vida propia más o menos independiente, pero que entran en una relación dialéctica con los lectores-habitantes de esas mismas urbes.

Son muchas más las novelas que bucean en la vida urbana, algunas también desde la mirada femenina. Estas novelas realizan un diálogo intertextual entre ellas y con los discursos que pueblan las ciudades. Y en ese diálogo constituyen una referencia de identidad importante para la vida nacional, porque releen el pasado, interpretan el presente y anuncian el futuro de las relaciones entre los colombianos. 


\section{La Escritura Femenina}

A lo largo del siglo, las mujeres van asomándose tímida y lentamente a la práctica literaria. En todos los géneros tenemos pioneras: poesía, crítica, narrativa. Hay que esperar sin embargo, hasta bien entrada la década del 70 para asistir a una presencia más significativa de la escritura femenina, de tal mailera, que por primera vez podemos hablar de un grupo de mujeres escritoras en el país: Alba Lucía Ángel, Helena Araujo, Marvel Moreno, María Elvira Bonilla, Fanny Buitrado, Katty Lizarazo y Flor Romero de Nohora.

Creo que todas realizan un aporte valioso y específico a la narrativa nacional. Por imposibilidad de extenderme más, me voy a detener únicamente en dos novelas que a mi juicio son bien importantes y en el conjunto del proceso constituyen hitos de significación y originalidad: "Estaba la Pájara Pinta Sentada en el Verde Limón”, Alba Lucía Ángel, 1975 y “Jaulas”, María Elvira Bonilla, 1984.

\section{La Pájara Pinta}

Con esta novela, Alba Lucía Ángel, incursiona en algunos períodos de nuestra historia, recuperando el punto de vista de la mujer.

La importancia de lo animico espiritual en los fentmenos de la historia habia sido subrayada ya por Dilthey y Simmel, mientras que Schopenhauer ofrecia una imagen de ella que sigue vigente hoy: una maraña de hilos que se cruzan al azar. Los autores de la generación del 98 (en España), que conocían bien la obra de estos filósofos, se acercaron a la historia con un enfoque nuevo: en vez de batallas y reyes, las vivencias del pueblo; en vez de progresión lineal, tiempo cíclico; en vez de una única visión "oficial", énfasis en la relatividad; en vez de tono elevado, uso de la ironía. Ya en la obra de ellos se da la desmitificación y se invita al lector a recomponer los fragmentos presentados por su propia cuenta. En las novelas de los últimos años escritas por mujeres se va a un más allá en cuanto a la modificación del discurso... Se pone énfasis en la posibilidad de una interpretación siempre nueva y relativa. (Birute, 1984)

Esta visión sintetiza mucho de lo conseguido por la autora en cuestión, a lo largo de su trabajo novelístico.

En la novela de Ángel desfila el país desde 1948 hacia adelante. El asesinato de Gaitán se convierte - como en muchas novelas - en punto de partida y de llegada. Pero no es sólo esta sombra, son también los estudiantes muertos el 8 y 9 de junio de 1954, las revueltas del 10 de mayo que anteceden al Frente Nacional, los Pájaros con León María Lozano a la cabeza. (La novela 
articula lo regional y lo nacional). Hay otras presencias que deambulan por la obra: Camilo Torres, el Ché Guevara, Fidel y la revolución Cubana y hasta Regis Debray. Voces y criterios de mujeres jóvenes y mayores pueblan el texto y revisan los acontecimientos. No se trata de destacar la figura de algunas mujeres, sino de recuperar su presencia, su voz y su subjetividad colectiva, en medio de los acontecimientos.

Esta novela, con una mirada radicalmente interior, visualiza trozos del país, desde el centro y desde la provincia, desde los procesos educativos y costumbres y desde los libros y lecturas. Y como otras obras en Colombia, desde el ayer descubre y anuncia el futuro.

El país fue llenándose de otrospájaros. Abarrotándose de asesinos. Cuajándose de muertos. Congestionándose de sangre. Poblándose de miedos. Rebosando injusticias. Hinchándose de oprobios contra el derecho humano. Cargándose, impregnándose, plagándose. Colmándose de gritos, de amenazas, de olores pestilentes, de rios en los que la corriente parecía tinta roja de tanto desangrarse liberales... y las ciudades se convirtieron en lugares oscuros de pasos presurosos (Angel, 1981)

Las palabras se atropellan y desbordan y la obra genera un lenguaje capaz de abarcar a la vez lo exterior e interior, el acontecer y el sentir, la mirada y la reflexión. Con este conjunto de obras, de las cuales hace parte, "Estaba la Pájara Pinta sentada en el Verde Limón”, se han acabado los panfletos “objetivos" sobre las múltiples violencias que azotaron en sus años al país y que lo continúan azotando.

\section{Jaulas}

Esta novela de María Elvira Bonilla, publicada en 1984 ha pasado bastante desapercibida ante la crítica colombiana. Como escritura femenina es, sin embargo, de lo más significativo y logrado en Colombia.

La protagonista de "Jaulas" evalúan y analizan el mundo desde un largo monólogo: "Para transmitir modos de percepción femenina se renuncia al lenguaje y las normas de composición forjadas por los hombres, se introduce un léxico diferente y se modifica el uso de la sintaxis. La narrativa adquiere puntos de contacto con procedimientos psicoanalítico s, pero también retrocede a la expresión primaria vigente antes de que se establecieran los cánones y códigos del mundo civilizado". (Birute, 1984) Desde ese monólogo, Kristal Ventura destruye el mundo que la ha inutilizado y busca las llaves de su posible libertad.

El lenguaje que se desboca a lo largo de la obra se convierte casi en la única posibilidad de salida para esa generación muriente. 
Porque la heroina de mi historia también habria salido a la calle, lo habría intentado, la vida está en la calle, ya lo digo, una heroina de carne y hueso, sin grandes pretensiones, sin excepcionalidad, como la vida de cualquier mujer, sin aventuras, protegida, sin exponerse demasiado, nada extraordinario, ni guerras, ni hazañas ni epopeyas, mi heroina también tragano entero, la procesión va por dentro, por dentro va la procesión, sin chistar, sólo que mi heroina hubiera, tal vez intentado superarlo, sin lograrlo ella tampoco, pero habria sido, eso sí seguro, una mujer duramente tierna, tenazmente débil, amargamente dulce y solidariamente frágil que jamás suscitar\{a piedad, ni caridad, ni congoja, porque habia sido capaz de hablar y hablar, exteriorizar lances y episodios, hablar sin tener que vender su integridad al precio de este silencio, de esta quietud, se habria salido con la suya, valiente para confrontar y aún sobreponerse a los tiempos más sombrios, tiempos sombrios estos que nos tocó vivir, porque ella tendría la fuerza que yo no tengo, el tesón, la solidez. (Bonila, 1984)

Desde esa visión lúcida y rebelde de una mujer, se trabaja el mismo Cali que atraviesa la novela de Andrés Caicedo. Qué viva la Música: Los mismos jóvenes en rebelión contra la generación anterior, la música, el grupo, la Universidad y la política...

La violencia familiar patriarcal adquiere especial importancia ... Pero en esta obra su protagonista ni se rinde ni es vencida. El monólogo permite ir muy a fondo en motivaciones, rechazos, búsquedas, sentimientos, evaluaciones. Nos encontramos con una búsqueda desesperada de valores y autenticidad. Kristal Ventura prefiere enmudecer desesperada antes que someterse. Su manera de romper la prisión interior de esa reflexión evaluadora que lo coloca a todo y a todos bajo su ojo crítico del que no escapa nada. La mirada de Kristal Ventura se hace protesta y la protesta se hace vida en la palabra.

Las mujeres entonces, completan este cuadro de nuestra narrativa en las dos últimas décadas, en las cuales se ha realizado un doble trabajo; de creatividad, originalidad y búsqueda a nivel del lenguaje, del discurso mismo novelístico; y a nivel de la profundización en nuestra historia y en los paradigmas que rigen y enmarcan nuestras identidades como nación, como pueblo, como ciudadanos, como hombres y mujeres. Recorrer las novelas que en Colombia se han publicado de 1970 hacia adelante, es recorrer nuestro pasado inmediato y remoto, nuestros interrogantes y respuestas, nuestros deseos, realizaciones y frustraciones, nuestros sueños y despertares más o menos dulces o amargos.

\section{Bibliografía}

Angel, Alba Lucía, 1981: Está la Pájara Pinta Sentada en el Verde Limón: Ed Plaza y Janés. 
Arévalo, Guillermo Alberto, 1994: "Luis Fayad, narrador de lo Contemporáneo" en Luz Mery

Giraldo (compiladora) La Novela Colombiana ante la Critica: 1975-1990: Univalle-Udad Javeriana. 1994

Birute Ciplijans, Kaite, 1984: La novela Femenina contemporánea (19701985). Hacia una tipología de la narración en primera personas, Barcelona: Ed. Anthropos.

Bonila, María Elvira, 1984: Jaulas: Planeta.

Gil Casado, Pablo, 1990: La novela deshumanizada española: 1958 1988: Editorial del Hombre.

Hausser, Arnold, 1974: Orígenes de la Literatura y del Arte modernos, Tomo III, Madrid. Ediciones Guadarrama

Pineda Botero, Álvaro, 1990 Del mito a la Postmodernidad, La novela colombiana del siglo XX Tercer Mundo Editores

Raymond L., Williams, 1991: Novelas y poder en Colombia Tercer Mundo Editores.

Romero, José Luis, 1984: Latinoamérica, las Ciudades y las Ideas. Editorial Siglo XXI, Capitulo 7: Las Ciudades Masificadas.

Ruiz Gómez, Darío, 1978: Hojas en el Patio: Instituto Colombiano de Cultura. 